\title{
Variáveis de Procedimentos de Ensino e de Testes na Construção de Sentenças com Compreensão ${ }^{1}$
}

\author{
Maria Elizângela Carvalho Sampaio \\ Grauben Assis ${ }^{2}$ \\ Marcelo Quintino Galvão Baptista \\ Universidade Federal do Pará
}

\begin{abstract}
RESUMO - O objetivo do estudo foi verificar o efeito de dois procedimentos de ensino sobre a composição e compreensão de sentenças em crianças. No Estudo 1, cinco crianças foram expostas ao ensino de relações condicionais, testes de equivalência, ensino por encadeamento de respostas, testes de produção de sentenças, testes de conectividade e testes de leitura com compreensão. No Estudo 2, quatro crianças foram expostas apenas ao ensino por encadeamento de respostas e testes subsequentes. Utilizou-se três conjuntos de estímulos: desenhos, palavras maiúsculas e minúsculas. Em ambos os estudos, todos os participantes construíram as novas sentença, mas a leitura com compreensão só foi observada no Estudo 1. Esses resultados demonstraram a emergência de novas sentenças. Conclui-se que os estímulos utilizados foram funcionalmente equivalentes.
\end{abstract}

Palavras-chave: equivalência de estímulos; relações ordinais; sentenças; leitura com compreensão.

\section{Teaching and Testing Procedural Variables in the Construction of Sentences with Comprehension}

\begin{abstract}
The objective of this study was to verify the effect of two teaching procedures for comprehension and composition of sentences with children. In the Study 1, five children were exposed to conditional relations training, equivalence tests, training through response chaining, sentences production tests, connectivity tests and reading with comprehension tests. In the Study 2, four children were exposed only to the training through response chaining and subsequent tests. Three sets of stimuli were used: drawings, upper case words and lower case words. In both studies, all participants produced the new sentences, but reading with comprehension was observed only in the Study 1. These results demonstrated the emergency of new sentences. It is concluded that the used stimuli were functionally equivalents.
\end{abstract}

Keywords: stimuli equivalence; ordinal relations; sentences; reading with comprehension.

Um estudo conceitual apresentado por Green, Stromer e Mackay (1993) descreve o paradigma de classes ordinais em contingências de três termos, envolvendo discriminação a partir da construção de cadeias comportamentais ou sobreposição de estímulos. Isso constitui uma expansão da proposta de Sidman (cf. 1994) sobre as relações entre estímulos dentro de uma classe de estímulos equivalentes, ao enfatizar a análise das relações entre estímulos em sequências e entre sequências ensinadas separadamente uma da outra, e o uso de testes comportamentais que avaliam se tais relações apresentam as propriedades de uma relação ordinal referidas adiante, isto é, irreflexividade, assimetria, transitividade e conectividade, descritas a partir da matemática por Stevens (1951).

$\mathrm{Na}$ irreflexividade, dada a sequência $\mathrm{A} \rightarrow \mathrm{B} \rightarrow \mathrm{C}$, qualquer um dos membros não pode anteceder ou seguir a si próprio.

1 Este trabalho é parte da Tese de Doutorado do primeiro autor, sob orientação do segundo. Os autores agradecem aos doutores Maria Martha da Costa Hübner e Romariz da Silva Barros pelas valiosas sugestões e apoio na realização deste trabalho, ao João Vicente do Nascimento pelo desenvolvimento do programa de controle e registro de dados comportamentais, e à Bolsista de Iniciação Científica (PIBIC/CNPq), Cristiane Franco Élleres, pelo apoio na coleta e tratamento dos dados.

2 Endereço para correspondência: Rua Jerônimo Pimentel, 426/1801, Bairro do Umarizal. Belém, PA. CEP 66.055-000. Fone/Fax: (91) 3201-7662.E-mail: ggrauben@gmail.com.
Em outras palavras, a relação "vem antes de" não pode ser verdadeira para um dado estímulo em relação a si próprio, ou seja, "A" não vem antes dele mesmo, "B" não vem antes dele mesmo etc. O mesmo vale para a relação "segue após". A assimetria refere-se à não inversão de ordem espacial ou temporal entre os membros de uma dada sequência. ou seja, se $A \rightarrow B$ então "B" não pode vir antes de "A". Assim, na relação "vem antes de", se "A" vem antes de "B" não é possível a relação simétrica, isto é, " $B$ " vir antes de " $A$ ". Na transitividade, dadas as sequências $\mathrm{A} \rightarrow \mathrm{B}$ e $\mathrm{B} \rightarrow \mathrm{C}$, observase a sequência $A \rightarrow C$. Isso porque,tendo as duas primeiras sequências um estímulo comum, a formação de um novo par de estímulos é possível. Desse modo, na relação "vem antes de", se "A" vem antes de "B" e "B" vem antes de "C", então "A" vem antes de "C". A conectividade caracteriza-se pela possibilidade de relacionar todos os membros de uma sequência entre si, sejam eles pares adjacentes ou não. Assim, se $\mathrm{A} \rightarrow \mathrm{B} \rightarrow \mathrm{C} \rightarrow \mathrm{D}$, então é possível criar pares $\mathrm{A} \rightarrow \mathrm{B}, \mathrm{A} \rightarrow \mathrm{C}$, $\mathrm{A} \rightarrow \mathrm{D}, \mathrm{B} \rightarrow \mathrm{C}, \mathrm{B} \rightarrow \mathrm{D}$ etc. Testes adicionais podem documentar a formação de classes ordinais equivalentes. Desse modo, Green e cols. (1993) argumentam que a associação dos paradigmas de equivalência e de relações ordinais, aliada ao uso de uma tecnologia de controle de estímulos, pode ser eficaz na documentação e descrição da aquisição de relações ordinais e, portanto, na formação de classes ordinais equivalentes. 
O estudo da sintaxe envolve a ordenação de palavras e como elas são agrupadas. A estrutura sintática de uma sentença indica a forma na qual as palavras da sentença estão relacionadas umas com as outras. As palavras são combinadas para formar sentenças. O indivíduo precisa ler a palavra seguinte sem esquecer da palavra lida anteriormente e compreender o significado da frase por inteiro. No estudo aqui apresentado, adota-se o termo compreensão da leitura, a partir do paradigma de equivalência proposto por Sidman e Tailby (1982), envolvendo a emergência de relações condicionais entre estímulos.

As relações entre as palavras utilizadas na linguagem, ou seja, as funções gramaticais exercidas por elas, numa sentença, são aprendidas. No ensino dessas funções, com base no paradigma de equivalência de estímulos, são relevantes as posições ocupadas pelas palavras na sentença; isto é, cada posição remete à classe gramatical da palavra - classe de adjetivos, classe de substantivos, classe de verbos etc. Por exemplo, um indivíduo pode vir a aprender, na língua portuguesa, que um adjetivo segue um substantivo; por exemplo, "carro preto", "boneca grande". O indivíduo pode ainda aprender que as palavras em uma classe são intercambiáveis como adjetivos (cores, formas, comprimento), outras funcionam como substantivos (objetos, animais, plantas), outras são verbos e assim por diante. Todos os adjetivos são equivalentes ou todos os substantivos são intercambiáveis em suas posições numa sentença.

Um estudo que avaliou empiricamente a utilização do paradigma da equivalência no estabelecimento de sentenças foi realizado por Yamamoto (1994). No estudo, o procedimento de ensino e de testes foi semelhante aos de Lazar (1977) e houve duas palavras como estímulos experimentais. Participou uma criança autista, na faixa etária de 6 anos e com comportamento vocal severamente limitado. Houve duas condições experimentais. Na primeira condição, o autor verificou se a criança era capaz de estabelecer relações emergentes a partir de duas relações condicionais ensinadas $-\mathrm{AB}$ e $\mathrm{AC}$, sendo apresentado o conjunto "A" (A1 — cor verde ou A2 - desenho de roupa) como modelo e os conjuntos "B" (B1 - cor preta e $\mathrm{B} 2$ - desenho de sapato $)$ ou " $\mathrm{C}$ " $(\mathrm{C} 1$ - cor vermelha ou $\mathrm{C} 2$ desenho de brinquedo), como comparações. O autor verificou a emergência de relações simétricas, transitivas e de equivalência com precisão de $100 \%$. Segundo Yamamoto, esses resultados indicaram que crianças autistas com severas limitações de controle de estímulos formam classes de estímulos equivalentes, sem ser a linguagem uma condição necessária para isso.

$\mathrm{Na}$ segunda condição experimental, houve o ensino de sequências com duas palavras (conjuntos de estímulos "B" e "C" usados no estabelecimento de relações condicionais). Ou seja, a criança foi ensinada, por meio de reforçamento social, a responder ao nome das cores $(\mathrm{B} 1$ ou $\mathrm{C} 1)$ e, em seguida, a responder ao nome dos objetos (B2 ou C2). Nos testes de produção de sequência com os estímulos do conjunto "A", a criança foi capaz de apontar primeiro a cor verde (A1) e, em seguida, o desenho de roupa (A2), produzindo sentenças com duas palavras. Porém, o autor não deixa claro como instruiu a tarefa para o participante (Yamamoto, 1994).

Com base nos resultados obtidos em estudos anteriores, realizados com o paradigma de equivalência de estímulos e responder sequencial, tendo palavras como estímulos, Yamamoto e Miya (1999) realizaram um estudo com três estudantes autistas que apresentavam problemas de linguagem. Os autores utilizaram um procedimento de ensino informatizado para construção de quatro sentenças formadas por quatro palavras. As sentenças consistiam de um sujeito (representado pela figura humana), um objeto (representado pelo desenho de uma fruta), um verbo e uma partícula da língua japonesa que especifica a sentença em voz ativa ou passiva. Durante o ensino, os participantes precisavam formar sentenças gramaticalmente corretas a partir do modelo visual apresentado. Por exemplo, quando o modelo era a figura de uma frase representando o ato de um homem a comer uma maçã, o participante deveria construir a sentença "João come uma maça", na tela do computador. Os resultados demonstraram a efetividade desse tipo de arranjo experimental no estabelecimento de sentenças com uma ordem apropriada das palavras. Em um segundo estudo, com os mesmos participantes, mas em que foi refinado o procedimento de ensino, os autores ensinaram o uso de partículas específicas da língua japonesa que determinam a ordem das palavras nas sentenças nas vozes ativa e passiva. Os resultados confirmaram a efetividade do procedimento de ensino para a formação de sentenças gramaticalmente corretas.

Recentemente, Assis, Élleres e Sampaio (2006) avaliaram se após o ensino da formação de pelo menos duas sentenças diferentes com um procedimento por encadeamento de respostas, emergiria a formação de novas sentenças. Inicialmente, cinco crianças pré-escolares eram expostas ao procedimento de emparelhamento de acordo com o modelo para o ensino das relações condicionais $\mathrm{AB}$ e $\mathrm{AC}$. Os estímulos A eram desenhos, os estímulos B eram palavras correspondentes aos desenhos grafadas em letras maiúsculas e os estímulos $\mathrm{C}$ eram palavras correspondentes aos desenhos grafadas em letras minúsculas. Testes das relações condicionais $\mathrm{BA} / \mathrm{CA}$ e de equivalência $\mathrm{BC} / \mathrm{CB}$ foram aplicados. Em seguida, foi introduzido o procedimento de ensino por encadeamento. Os estímulos utilizados eram nove palavras escritas em português; essas palavras formavam três sentenças com três palavras cada uma. Durante o ensino da sentença 1 (UM SAPATO PRETO), o experimentador fornecia a seguinte instrução mínima ao participante: "Você está vendo essa palavra? Você tem que tocar levemente na tela e sempre que você fizer isso certo, vai aparecer uma figura e você verá uma mensagem do computador". Na primeira tentativa, a palavra UM era apresentada na "janela" presente na "área de escolha", enquanto as demais janelas permaneceram desativadas. Um toque do participante na palavra fazia com que ela se deslocasse da "área de escolha" para a "área de construção". Após essa resposta, uma animação gráfica era apresentada na tela com a mensagem: "Muito bem", "Você acertou!" ou "Parabéns!". Além disso, o pesquisador fornecia consequências verbais: "Legal!", "Você conseguiu!", e uma ficha plástica era depositada num recipiente plástico. Em seguida, apareciam as palavras UM e SAPATO em duas "janelas" na "área de escolha", e quando o participante tocava cada palavra, a mesma se deslocava da "área de escolha" para a "área de construção", lá permanecendo da esquerda para a direita por $2 \mathrm{~s}$. Poste- 
riormente, três palavras eram simultaneamente apresentadas (UM, SAPATO e PRETO) e o procedimento era repetido. A sentença 2 (UM BONECO BRANCO) era ensinada da mesma forma. Após esse treino, o participante era exposto a uma linha de base com as duas sentenças ensinadas se alternando na tela, três vezes consecutivas, sem erro. Nos testes de conectividade subsequentes, o participante era exposto às relações entre as duas sentenças ensinadas. As palavras das sentenças 1 e 2 eram apresentadas de forma alternada, por exemplo: $\mathrm{UM} \rightarrow \mathrm{SAPATO} \rightarrow \mathrm{BRANCO}$ e/ou $\mathrm{UM} \rightarrow \mathrm{BONECO} \rightarrow$ PRETO. Finalmente, a sentença 3 (UM CAVALO CINZA) era ensinada. Uma nova linha de base com as sentenças 1 e 3 ou 2 e 3 se alternando era conduzida e testes de conectividade envolvendo as palavras das três sentenças eram aplicados. Os resultados mostraram a formação de seis novas sentenças sem qualquer ensino adicional. Os autores discutem esses efeitos como decorrentes do tipo de procedimento adotado e da posição que cada estímulo ocupou na sequência.

O objetivo do presente estudo foi verificar o efeito de dois procedimentos de ensino sobre a composição e compreensão de sentenças em crianças. Uma questão que norteou a pesquisa foi: o ensino de relações condicionais e a formação de classes de estímulos equivalentes facilitariam o processo de composição de sentenças?

No Estudo 1, a partir da utilização de um procedimento de emparelhamento com o modelo para o ensino de relações condicionais, um procedimento de ensino por encadeamento de respostas para a produção de sentenças e um procedimento de testes para averiguar relações emergentes e compreensão de leitura envolvendo palavras, buscou-se verificar a construção de novas sentenças e a garantia de leitura das mesmas com compreensão.

No Estudo 2, procurou-se avaliar o efeito da remoção do ensino de relações condicionais, ou seja, da manutenção exclusiva do ensino por encadeamento, com as palavras usadas no Estudo 1 para composição de sentenças. Verificou-se a emergência de relações ordinais com a formação de novas sentenças gramaticalmente corretas, porém sem compreensão de leitura.

\section{Estudo 1}

\section{Método}

\section{Participantes}

Participaram do estudo cinco crianças, de ambos os gêneros, com a idade variando entre 6 anos e 1 mês e 6 anos e 6 meses, que cursavam a primeira série do Ensino Fundamental de uma escola da Rede Pública Municipal. O convite para participarem do estudo foi feito por meio de entrevista com a professora. O estudo foi aprovado pelo Comitê de Ética da Universidade Federal do Pará, conforme exigência da Resolução 196/96 do Conselho Nacional de Saúde e da Resolução 016/2000 do Conselho Federal de Psicologia.

\section{Ambiente e equipamento}

As sessões experimentais foram conduzidas em uma sala da escola, climatizada e com relativo isolamento acústico. As sessões duravam, no máximo, 25 minutos.

Foi utilizado um microcomputador modelo IBM PENTIUM de $300 \mathrm{MHz}$, com monitor de 15'. Um programa (REL na versão 3.0 for Windows - Santos, Silva, Baptista \& Assis, 1997) elaborado em linguagem Visual Basic $6 \AA$ apresentava os estímulos, os números de tentativas e as posições que cada estímulo ocupava na tela, além de efetuar o registro das respostas corretas e incorretas.

Três conjuntos de estímulos foram usados: Conjunto "A", formado por desenhos; Conjunto "B", por palavras com letras maiúsculas; e Conjunto "C", por palavras com letras minúsculas. As palavras eram formadas por artigo definido ou indefinido, substantivo concreto, verbo e advérbio.

\section{Procedimento}

Procedimentos especiais, como o uso de questionários e entrevistas dirigidas, foram adotados para identificar alguns reforçadores para os participantes. Aplicou-se um questionário aos pais para que respondessem questões referentes às preferências de seu filho(a) sobre brinquedos, jogos, guloseimas, filmes e desenhos. Durante as entrevistas, os participantes indicaram suas preferências de guloseimas, jogos, brinquedos e outras atividades lúdicas. Esses dados serviram para oferecer ao participante "brindes" após cada sessão experimental, algumas no mesmo dia, com intervalos de 20 minutos, independentemente do desempenho do participante.

O experimento compreendeu duas fases, cada uma com várias etapas. Na Fase I, as seguintes etapas foram programadas:

Etapa 1: Pré-teste. Nessa etapa, os participantes foram submetidos a um pré-teste com o objetivo de verificar o repertório de leitura fluente de sentenças. Os participantes liam palavras isoladas, reconheciam e nomeavam figuras. Por exemplo, a experimentadora apresentava, por meio de um álbum plastificado, uma das sentenças previstas para essa etapa de ensino. As palavras foram escritas em letras maiúsculas, pretas, tamanho 48 e no formato times new roman. Em seguida, solicitava que o participante lesse em voz alta a frase corretamente. As três sentenças previstas na fase de ensino foram utilizadas.

Etapa 2: Ensino por Identidade. Nessa etapa, foram ensinadas, por meio de um procedimento de emparelhamento com o modelo (matching to sample), as relações de Identidade AA (desenho/desenho), BB (palavras escritas em letras maiúsculas/palavras escritas em letras maiúsculas) e $\mathrm{CC}$ (palavras escritas em letras minúsculas/palavras escritas em letras minúsculas). Para isso, usou-se alguns dos desenhos, palavras em letras maiúsculas e palavras em letras minúsculas dos conjuntos A, B e C (ver Figuras 1 e Quadro 1). Cada relação condicional era ensinada em um bloco com 12 tentativas. Cada resposta correta produzia uma animação gráfica na tela e reforços sociais pela experimentadora ("muito 


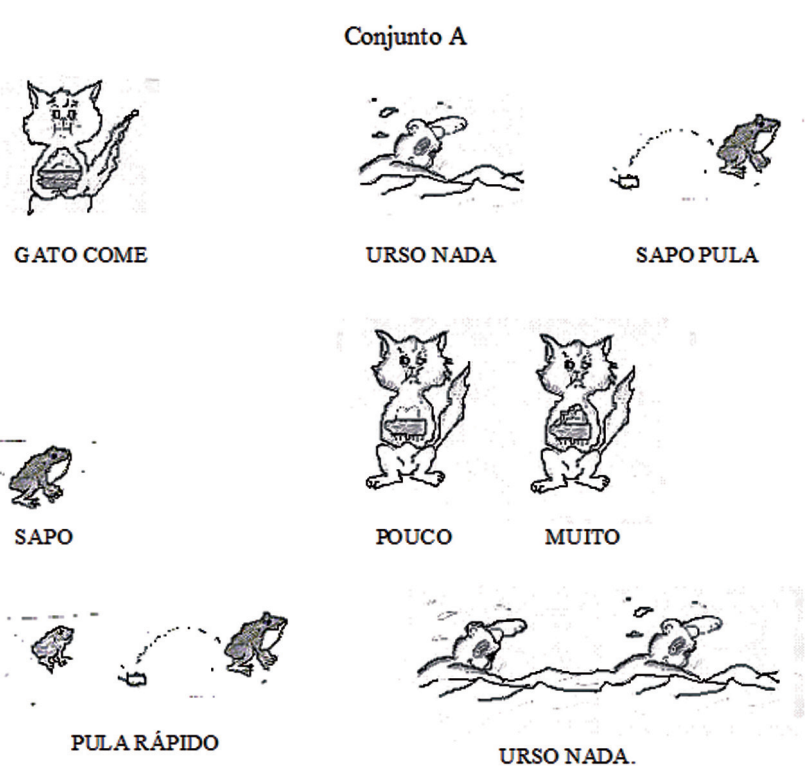

Figura 1. Desenhos esquemáticos do Conjunto A.

Quadro 1. Palavras escritas dos conjuntos B e C.

Conjunto B: palavras escritas em letras maiúsculas

\begin{tabular}{|cll|}
\hline O & UM & \\
URSO & SAPO & GATO \\
COME & PULA & NADA \\
POUCO & MUITO & RÁPIDO \\
\hline
\end{tabular}

Conjunto $\mathrm{C}$ : palavras escritas em letras minúsculas

\begin{tabular}{|ccc|}
\hline o & um & \\
urso & sapo & gato \\
come & pula & nada \\
pouco & muito & rápido \\
\hline
\end{tabular}

bem", "legal", “certo"). Respostas diferentes produziam um escurecimento da tela por $3 \mathrm{~s}$ e a reapresentação da mesma configuração de estímulos (procedimento de correção). As instruções mínimas eram "toque na figura (modelo presente). Agora, toque na outra figura (os três estímulos de comparação estavam presentes simultaneamente)". O ensino de cada relação era concluído quando o participante alcançasse o critério de acerto, isto é, responder corretamente três vezes consecutivas.

Etapa 3: Teste de Reflexividade. Houve, nessa etapa, também por meio de um procedimento de emparelhamento com o modelo, a aplicação de testes de reflexividade (desenho/desenho, palavras escritas em letras maiúsculas/palavras escritas em letras maiúsculas e palavras escritas em letras minúsculas/palavras escritas em letras minúsculas), sendo utilizados estímulos dos conjuntos A, B e C não incluídos no ensino por identidade. Não havia consequências diferenciais para as respostas dos participantes. Caso o participante não respondesse corretamente na primeira tentativa do teste (responder prontamente), teria mais uma oportunidade de responder (resposta com atraso). Se continuasse a responder diferente do programado, retornava à etapa de ensino imediatamente anterior. Caso as respostas fossem corretas, avançava para a etapa seguinte.

Etapa 4: Ensino de Relações Condicionais Arbitrárias. Todos os participantes foram expostos ao ensino de duas relações condicionais (AB/AC). O objetivo era ensinar cada participante a relacionar as figuras (conjunto A) com as palavras em letras maiúsculas (conjunto $\mathrm{B}$ ) e em letras minúsculas (conjunto $C$ ) que iriam formar as sentenças utilizadas nas fases posteriores do estudo. Nessa etapa, a configuração dos estímulos na tela, as instruções fornecidas aos participantes, as consequências diferenciais apresentadas e o critério de acerto foram os mesmos descritos na Etapa 2.

Etapa 5: Teste de Relações Simétricas. A configuração dos estímulos na tela, as instruções fornecidas aos participantes e o critério para finalizar o teste foram os mesmos descritos na Etapa 3. Nessa etapa foram testadas as relações B/A e C/A. Como nos demais testes, consequências diferenciais não foram apresentadas.

Etapa 6: Linha de Base. Nessa etapa, a configuração dos estímulos na tela, as instruções fornecidas aos participantes e as consequências diferenciais apresentadas foram as mesmas descritas na Etapa 2, com reforços sociais. Os estímulos foram os mesmos da Etapa 4. No ensino das relações condicionais $\mathrm{AB}$ e AC que formavam a linha de base, as tentativas foram apresentadas alternativamente em um bloco de 18 tentativas, com três tentativas para cada relação ensinada. O critério de acerto era o mesmo da Etapa 2.

Etapa 7: Teste de Equivalência. A configuração dos estímulos na tela e as instruções foram as mesmas descritas na Etapa 3. Esse teste teve por objetivo verificar a emergência de relações condicionais entre os estímulos do conjunto $\mathrm{B}$ e C. Os testes das relações condicionais BC (B1C1, B2C2 e $\mathrm{B} 3 \mathrm{C} 3$ ) foram apresentados em blocos de 12 tentativas, sem consequências diferenciais. $\mathrm{O}$ critério de conclusão era $\mathrm{o}$ mesmo da Etapa 3.

$\mathrm{Na}$ Fase II, foram ensinadas e testadas três sentenças de quatro palavras, escritas em português. As palavras exerciam as seguintes funções: artigo definido/indefinido, substantivo concreto, verbo e advérbio. As etapas dessa fase são descritas a seguir:

Etapa 1: Ensino por Encadeamento I. Nessa etapa foi ensinada a Sentença 1 - O SAPO PULA RÁPIDO. A experimentadora fornecia a seguinte instrução mínima ao participante: "Você está vendo essa palavra? Você tem que tocar levemente na tela e sempre que você fizer isso corretamente, vai aparecer uma figura em movimento, você ouvirá uma mensagem do computador e eu darei a você uma ficha".

Os estímulos foram apresentados na tela do computador que estava dividida em duas áreas principais. A parte superior da tela, com fundo da cor cinza, era denominada "área de construção" e apresentava cinco "janelas" de 2,5 cm x 2,5 cm 
cada dispostas lado a lado e a parte inferior era denominada "área de escolha". Nessa área, os estímulos (palavras) foram apresentados de forma randomizada, em cinco "janelas" de $2,5 \mathrm{~cm} \times 2,5 \mathrm{~cm}$ cada uma. A tarefa do participante era tocar em uma "janela". A experimentadora, então, acionava o mouse com o cursor sobre a "janela" e o estímulo se deslocava para a primeira "janela" imediatamente à esquerda na "área de construção".

Na primeira tentativa, uma palavra era apresentada na "janela" disponível na "área de escolha". Por exemplo, a palavra "O" era apresentada nessa "janela", enquanto as demais permaneciam vazias (desativadas). Um toque sobre a palavra produzia seu deslocamento da "área de escolha" para a "área de construção", na qual ficava disposta por 2 s. Em seguida, duas janelas eram ativadas de modo que, além da palavra "O", outra palavra era adicionada, por exemplo, "SAPO". A tarefa do participante era tocar na palavra "O" e, logo depois, na palavra "SAPO", as quais eram deslocadas para a "área de construção", ficando a primeira palavra tocada à esquerda e a segunda, à direita, durante 2 s. Em seguida, a mesma sequência de eventos ocorria com a introdução gradativa das duas outras palavras (e.g., PULA e RÁPIDO).

Quando a ordenação das palavras era correta, eram apresentadas as consequências diferenciais já descritas na Fase I (animação gráfica na tela e reforços sociais). Se o participante ordenasse a sentença completa corretamente três vezes consecutivas, a experimentadora lia em voz alta e apontava a sentença, sendo iniciada a Etapa 2. Quando a ordenação das palavras não era correta (e.g., SAPO $\rightarrow \mathrm{O}$ ), não havia consequência reforçadora, a tela se embranquecia por um intervalo de $3 \mathrm{~s}$ e os mesmos estímulos eram reapresentados na "área de escolha", na mesma posição. Caso ele não ordenasse a sentença completa corretamente, retornava ao passo com duas palavras.

Etapa 2: Teste de Produção da Sentença I. O teste tinha a função de avaliar a efetividade do ensino e a ordinalidade da sentença ensinada. Nesse teste, todas as palavras que formavam a Sentença 1 foram apresentadas simultaneamente em "janelas" dispostas lado a lado, na "área de escolha".

Etapa 3: Ensino por Encadeamento II. O ensino tinha como objetivo a formação da Sentença 2 - UM GATO COME MUITO. Houve os mesmos passos descritos para o ensino da Sentença I (ver Etapa 1).

Etapa 4: Teste de Produção da Sentença II. Esse teste envolveu as palavras da Sentença II. Teve o mesmo objetivo do Teste de Produção da Sequência I e sua aplicação seguiu os mesmos passos descritos para aquele teste (ver Etapa 2).

Etapa 5: Revisão da Linha de Base com as Sentenças I e II. O objetivo dessa etapa era assegurar um responder estável antes de submeter o participante às contingências de testes. Ou seja, as duas sentenças eram ensinadas alternadamente, de acordo com os passos descritos nas etapas 1 e 3 .

Etapa 6: Teste de Conectividade I. Esse teste foi realizado com os estímulos das duas sentenças ensinadas: O SAPO PULA RÁPIDO e UM GATO COME MUITO. As palavras das Sentenças I e II foram apresentadas randomicamente na “área de escolha", sendo apresentados os mesmos passos já descritos para os testes das etapas 2 e 4.

Etapa 7: Ensino por Encadeamento III. O ensino tinha como objetivo a formação da Sentença III - UM URSO NADA POUCO. Houve os mesmos passos descritos para o ensino da Sentença I e da Sentença III (ver Etapa 1).

Etapa 8: Teste de Produção da Sentença III. Nesse teste foram utilizadas as palavras da Sentença III. Teve o mesmo objetivo dos testes de produção das sequências anteriores e sua aplicação seguiu os mesmos passos já descritos.

Etapa 9: Revisão da Linha de Base com as Sentenças I e III. Essa etapa teve os mesmos objetivos e critérios da Etapa 5.

Etapa 10: Teste de Conectividade II. Esse teste envolveu as palavras das sentenças I e III,: "O SAPO PULA RÁPIDO" e "UM URSO NADA POUCO”, respetivamente.

Etapa 11: Revisão de Linha de Base com as Sentenças II e III. Essa etapa apresentou os mesmos objetivos e critérios da Etapa 5.

Etapa 12: Teste de Conectividade III. Nesse teste foram utilizadas as palavras das duas sentenças II e III: "UM GATO COME MUITO" e "UM URSO NADA POUCO", respectivamente. Houve os mesmos passos descritos para os testes de conectividade aplicados anteriormente.

Etapa 13: Teste de Compreensão de Leitura. Esse teste teve como objetivo avaliar se os participantes liam com compreensão as sentenças cuja composição fora ensinada. Cada sentença foi apresentada uma única vez. A aplicação do teste ocorreu em duas sub-etapas, conforme descrição a seguir:

$\mathrm{Na}$ primeira sub-etapa, o participante teve que responder na presença de uma figura, por exemplo, de um sapo comendo rápido, como modelo, e quatro sentenças diferentes, por exemplo, "O SAPO PULA MUITO”, "O SAPO COME MUITO”, "UM GATO PULA RÁPIDO” e "UM SAPO COME RÁPIDO", como estímulos de comparação. A experimentadora falava ao participante: "Aponte e leia em voz alta a sentença correta". O participante precisava apontar a sentença que correspondia à figura modelo.

Utilizaram-se figuras correspondentes às sentenças, desenhadas em uma folha de papel e quatro sentenças escritas em letras maiúsculas na cor preta e fonte times new roman, tamanho 20. Não foram programadas consequências diferenciais para o responder e o participante foi exposto ao teste até duas vezes, no máximo, caso respondesse diferente do programado na primeira tentativa.

$\mathrm{Na}$ segunda sub-etapa, foi apresentada uma sentença escrita em letras maiúsculas como modelo, por exemplo, “O GATO PULA MUITO” e quatro figuras como estímulos de comparação, por exemplo, um sapo comendo muito, um gato comendo pouco, um urso pulando pouco e um gato pulando muito. A tarefa do participante era apontar a figura correspondente à sentença apresentada. A experimentadora falava ao participante: “Aponte a figura correta". Seis novas sentenças correspondentes às seis figuras foram usadas como modelo no teste, uma sentença de cada vez. Independentemente dos resultados obtidos, todos eram expostos às duas sub-etapas. 
Tabela 1. Número de respostas corretas pelo número total de respostas requeridas, para cada participante, no treino das relações condicionais $\mathrm{AB} / \mathrm{AC}$ e testes de simetria BA/CA, do Estudo 1.

\begin{tabular}{lcccccc}
\hline \hline Relações Ensinadas & Relações Testadas & MAI & RAF & RAC & ISA & GAB \\
\hline Linha de base AB & & $3 / 3$ & $3 / 3$ & $3 / 3$ & $3 / 3$ & $3 / 3$ \\
& Simetria BA & $1 / 1$ & $1 / 1$ & $1 / 1$ & $1 / 1$ & $1 / 1$ \\
Linha de base AC & & $3 / 3$ & $3 / 3$ & $3 / 3$ & $3 / 3$ & $3 / 3$ \\
& Simetria CA & $1 / 1$ & $1 / 1$ & $1 / 1$ & $1 / 1$ & $1 / 1$ \\
\hline \hline
\end{tabular}

Nota - 3/3 alcançou o critério de acerto na primeira exposição; 1/1 respondeu prontamente na primeira tentativa.

\section{Resultados}

Os seguintes resultados foram obtidos na Fase I:

\section{Pré-teste}

Todos os participantes apresentaram um repertório limitado, ou seja, liam algumas palavras, isoladamente, mas não apresentavam uma leitura fluente de sentenças.

\section{Ensino por identidade e teste de reflexividade}

Todos os participantes (MAI, RAF, RAC, ISA e GAB) alcançaram o critério de acerto no treino por identidade entre desenhos (A/A), palavras em letras maiúsculas $(\mathrm{B} / \mathrm{B})$ e palavras em letras minúsculas $(\mathrm{C} / \mathrm{C})$, na primeira exposição. Nos testes de reflexividade, todos os participantes responderam corretamente.

\section{Ensino de relações condicionais arbitrárias e testes de relações simétricas}

No ensino de relações condicionais, todos os participantes alcançaram o critério de acerto na primeira exposição. Nos testes de relações simétricas, todos responderam corretamente na primeira tentativa.

\section{Linha de base e testes de simetria}

Todos os participantes obtiveram $100 \%$ de acertos no ensino da Linha de Base, alcançando o critério de acerto na primeira exposição. Nos testes de relações simétricas B/A e C/A, todos os participantes responderam corretamente na primeira tentativa (ver Tabela 1):

\section{Testes de equivalência com o conjunto de estímulos B e C}

Os participantes obtiveram $100 \%$ de acertos tanto no bloco $\mathrm{BC}$ quanto no bloco $\mathrm{CB}$ (testes de equivalência), demonstrando a emergência de novas classes que não tinham sido diretamente ensinadas (ver Tabela 2).

$\mathrm{Na}$ Fase II, os seguintes resultados foram observados:

\section{Ensino por encadeamento e testes de produção de sentenças}

Os participantes responderam a todos os testes de produção de sentenças com $100 \%$ de precisão, após o ensino por encadeamento.

\section{Revisão de linha de base}

Os participantes MAI, RAF e RAC alcançaram o critério de acertos quando submetidos à revisão de linha de base das Sentenças I, II e III (ver Tabela 3). Já os participantes ISA e GAB precisaram de mais três exposições para alcançar o critério de acerto, nas três sentenças ensinadas.

\section{Testes de conectividade}

Nos testes de conectividade (ver Tabela 4), os participantes MAI, RAF e RAC ordenaram corretamente as novas sentenças na primeira tentativa. Entretanto, dois outros participantes, ISA e GAB, responderam com atraso (na segunda

Tabela 2. Número de respostas corretas pelo número total de respostas requeridas, para cada participante, nos testes de equivalência das relações $\mathrm{BC}$ e $\mathrm{CB}$ do Estudo 1.

\begin{tabular}{llllll}
\hline \hline Relações Testadas & MAI & RAF & RAC & ISA & GAB \\
\hline Relações BC & $1 / 1$ & $1 / 1$ & $1 / 1$ & $2 / 2$ & $1 / 1$ \\
Relações CB & $1 / 1$ & $1 / 1$ & $1 / 1$ & $2 / 2$ & $2 / 2$ \\
\hline \hline
\end{tabular}

Nota $-1 / 1$ respondeu prontamente na primeira tentativa; $2 / 2$ respondeu na segunda tentativa. 
Tabela 3. Número de respostas corretas pelo número total de respostas requeridas, para cada participante, em cada sentença ensinada nas revisões de linha de base do Estudo 1.

\begin{tabular}{|c|c|c|c|c|c|}
\hline Revisão de Linha de Base & MAI & RAF & RAC & ISA & GAB \\
\hline "O sapo pula rápido" & $3 / 3$ & $3 / 3$ & $3 / 3$ & $6 / 3$ & $6 / 3$ \\
\hline "Um gato come muito" & $3 / 3$ & $3 / 3$ & $3 / 3$ & $6 / 3$ & $6 / 3$ \\
\hline "O urso nada pouco" & $3 / 3$ & $3 / 3$ & $3 / 3$ & $6 / 3$ & $6 / 3$ \\
\hline
\end{tabular}

Nota - 3/3 participante alcançou o critério de acerto na primeira exposição à sentença completa; 6/3 participante alcançou o critério de acerto na sexta exposição à sentença completa.

tentativa) em três sentenças: "UM SAPO COME RÁPIDO", "O SAPO NADA RÁPIDO” e "UM URSO COME MUITO”.

\section{Testes de compreensão de leitura}

Nos testes de compreensão de leitura das seis novas sentenças, todos os participantes responderam corretamente na primeira tentativa.

\section{Discussão}

Os resultados obtidos demonstram a efetividade do arranjo experimental para o estabelecimento de classes de equivalência (semântica), corroborando a afirmativa de de Rose (1993):

....dizer que uma palavra tem um significado implica que esta palavra é um estímulo equivalente a um conjunto de estímulos, que correspondem a objetos, eventos, qualidades ou ações. Esta classe de estímulos a que a palavra se tornou equivalente é o significado. Estas relações de equivalência permitem a produção e a compreensão da linguagem. (p. 249)

As palavras que compuseram as sentenças envolviam substantivos concretos (sapo, urso, gato), ações (pular, nadar e comer) e quantidades/qualidades (muito, pouco, rápido). Conforme a taxonomia skinneriana (Skinner, 1992, p. 394), o artigo ("O”, "UM") e os advérbios ("MUITO", "POUCO”) são autoclíticos quantificadores, indicando referência a um organismo em particular (urso, sapo, gato). As palavras "SAPO", "URSO" e "GATO" são tactos elementares e os verbos "PULA", "COME" e "NADA" são autoclíticos relacionais, que especificam uma propriedade do organismo em particular do qual se está falando. Uma importante contribuição da presente pesquisa pode ser entendida no sentido de que as unidades verbais contendo essas palavras foram manipuladas experimentalmente, como estímulos, em termos de ensino de relações envolvendo essas unidades e no teste de novas relações baseadas no ensino. O uso dessas unidades (palavras) para a formação de sentenças possibilitou demonstrar sua funcionalidade, como Skinner propôs ao formular a classificação desses componentes. Ainda, a manipulação experimental que levou à formação de sentenças pode ser vista como uma contribuição para a discussão semântica, no âmbito da Análise do Comportamento.

Os resultados também replicam sistematicamente Assis, Élleres e Sampaio (2006), estendendo para quatro palavras a formação de sentenças com compreensão de leitura.

Os desempenhos dos participantes submetidos ao ensino por encadeamento mostram que todos responderam consistentemente às sentenças cuja formação foi ensinada na linha de base e também formaram seis novas sentenças, evidenciando uma ampliação do controle de estímulos.

Dois participantes (ISA e GAB) responderam na segunda tentativa, ou seja, com atraso, em três sentenças: "UM SAPO COME RÁPIDO”, “O SAPO NADA RÁPIDO”, "UM URSO COME MUITO”. A literatura tem mostrado que esse responder com atraso evidencia que a equivalência nem sempre ocorre na primeira tentativa (Green \& Saunders, 1998). Porém, todas as cinco crianças foram capazes de ler com compreensão.

Tabela 4. Número de respostas corretas pelo número total de respostas requeridas, em cada sentença, para cada participante, nos testes de conectividade I, II e III, do Estudo 1.

\begin{tabular}{lccccc}
\hline \hline Testes de Conectividade & MAI & RAF & RAC & ISA & GAB \\
\hline UM SAPO COME RÁPIDO (I) & $1 / 1$ & $1 / 1$ & $1 / 1$ & $2 / 2$ & $2 / 2$ \\
UM GATO PULA MUITO (I) & $1 / 1$ & $1 / 1$ & $1 / 1$ & $1 / 1$ & $1 / 1$ \\
O SAPO NADA RÁPIDO (II) & $1 / 1$ & $1 / 1$ & $1 / 1$ & $2 / 2$ & $2 / 2$ \\
O URSO PULA POUCO (II) & $1 / 1$ & $1 / 1$ & $1 / 1$ & $1 / 1$ & $1 / 1$ \\
O GATO NADA MUITO (III) & $1 / 1$ & $1 / 1$ & $1 / 1$ & $1 / 1$ & $1 / 1$ \\
UM URSO COME MUITO (III) & $1 / 1$ & $1 / 1$ & $1 / 1$ & $2 / 2$ & $2 / 2$ \\
\hline
\end{tabular}

Nota - 1/1 participantes responderam prontamente na primeira tentativa; $2 / 2$ participantes responderam na segunda tentativa. 
Tabela 5. Número de respostas corretas pelo número total de respostas requeridas, em cada sentença cuja formação foi ensinada com todas as quatro palavras, para cada participante, durante o ensino por encadeamento I, II e III, do Estudo 2.

\begin{tabular}{lcccc}
\hline \hline Ensino por Encadeamento & LEO & TER & IVO & $5 / 3$ \\
\hline "O sapo pula rápido" & $3 / 3$ & $5 / 3$ & $3 / 3$ & $3 / 3$ \\
"Um gato come muito" & $4 / 3$ & $3 / 3$ & $3 / 3$ & $3 / 3$ \\
"O urso nada pouco" & $3 / 3$ & $3 / 3$ & $3 / 3$ \\
\hline \hline
\end{tabular}

Nota - 3/3 participante alcançou o critério de acertos; 4/3 participante foi exposto quatro vezes à sequência; $5 / 3$ participante foi exposto cinco vezes à sequência.

Os resultados apontam para a utilidade do paradigma de equivalência de estímulos sequenciais no ensino da sintaxe, a partir de contingências de três termos, corroborando a proposta de Green e cols. (1993).

Com o refinamento do procedimento adotado e redução da exposição às contingências de ensino e testes, programou-se um segundo estudo para avaliar se crianças que não liam sentenças fluentemente poderiam construir e compreender novas sentenças, usando unicamente o ensino por encadeamento de palavras.

\section{Estudo 2}

\section{Método}

\section{Participantes}

Participaram quatro crianças, de ambos os gêneros, alunos da primeira série do Ensino Fundamental de uma escola da Rede Pública Municipal. Os alunos foram de uma faixa etária de 5 anos e 10 meses a 6 anos e 11 meses. O recrutamento foi realizado por meio de entrevista com a professora. $\mathrm{O}$ estudo também foi aprovado pelo Comitê de Ética da mesma Universidade do Estudo 1.

\section{Ambiente e equipamento}

Utilizou-se o mesmo espaço físico, equipamento e software do Estudo 1.

\section{Estímulos}

Os estímulos utilizados foram as mesmas sentenças usadas nos procedimentos de ensino por encadeamento, testes de produção de sentenças, de conectividade e de compreensão de leitura do Estudo 1.

\section{Procedimento}

Este estudo contou com as mesmas etapas de pré-testes, ensino por encadeamento, testes de produção de sentenças, revisão da linha de base e testes de conectividade da Fase II do Estudo 1, inclusive com os testes de compreensão de leitura.

\section{Resultados}

\section{Pré-teste}

Todos os participantes apresentaram o mesmo repertório limitado dos participantes do Estudo 1, ou seja, liam algumas palavras, isoladamente, mas não apresentavam uma leitura fluente de sentenças.

\section{Ensino por encadeamento}

Os participantes LEO, TER, IVO e MEI foram submetidos a um procedimento de ensino por Encadeamento com 4 palavras para a formação das sentenças 1 ("O SAPO PULA RÁPIDO”), 2 ("UM GATO COME MUITO") e 3 ("O URSO NADA POUCO”).

Todos os participantes alcançaram o critério de acerto na formação das sentenças 1, 2 e 3 (ver Tabela 5). Porém dois participantes (TER e IVO) precisaram de mais duas exposições na sentença "O SAPO PULA RÁPIDO" para alcançar o critério de acertos. Um participante (LEO) precisou de uma re-exposição na sentença "UM GATO COME MUITO”.

Tabela 6. Número de respostas corretas pelo número total de respostas requeridas, em cada sequência, para cada participante, durante os testes de produção de sequências I, II e III, do Estudo 2.

\begin{tabular}{lcccc}
\hline \hline Teste de Produção de Sequências & LEO & TER & IVO & MEI \\
\hline "O sapo pula RÁPIDO" & $1 / 1$ & $1 / 1$ & $1 / 1$ & $1 / 1$ \\
"Um gato come MUITO" & $1 / 1$ & $1 / 1$ & $1 / 1$ & $1 / 1$ \\
"O urso nada pouco" & $1 / 1$ & $1 / 1$ & $1 / 1$ \\
\hline \hline
\end{tabular}

Nota - 1/1 participante respondeu na primeira tentativa. 
Tabela 7. Número de respostas corretas pelo número total de respostas requeridas, para cada participante, nas três sentenças da revisão de linha de base, do Estudo 2.

\begin{tabular}{|c|c|c|c|c|}
\hline Revisão de Linha de Base & LEO & TER & IVO & MEI \\
\hline "O sapo pula rápido" & $5 / 3$ & $5 / 3$ & $5 / 3$ & $3 / 3$ \\
\hline "Um gato come muito" & $3 / 3$ & $3 / 3$ & $3 / 3$ & $3 / 3$ \\
\hline “O urso nada pouco" & $3 / 3$ & $3 / 3$ & $3 / 3$ & $5 / 3$ \\
\hline
\end{tabular}

Nota - 3/3 participante alcançou o critério de acertos na primeira exposição; $5 / 3$ participante foi exposto cinco vezes à sequência.

\section{Testes de produção de sentenças}

Em seguida, os participantes foram expostos ao teste de produção de sentenças. Os participantes responderam a todos os testes de produção de sentenças com 100\% de acerto em cada tentativa (ver Tabela 6).

\section{Revisão de linha de base}

Todos os participantes alcançaram o critério de acertos quando submetidos à revisão de linha de base das sentenças I, II e III (ver Tabela 7). Entretanto, três participantes (LEO, TER e IVO) precisaram de cinco exposições à sentença “O SAPO PULA RÁPIDO". Um participante (MEI) precisou de cinco exposições à sentença "O URSO NADA POUCO".

\section{Testes de conectividade}

Nos testes de conectividade, todos os participantes ordenaram corretamente as seis novas sentenças. Três participantes, LEO, TER e IVO responderam com atraso às sentenças "O SAPO NADA RÁPIDO" " "UM SAPO COME RÁPIDO” (ver Tabela 8).

\section{Testes de compreensão de leitura}

Nos testes de compreensão de leitura, os participantes não leram fluentemente as seis novas sentenças.

\section{Discussão}

Este estudo teve com objetivo verificar se após o ensino da formação de três sentenças diferentes com quatro palavras, usando exclusivamente um procedimento por encadeamento de respostas, crianças que não apresentavam um repertório de leitura fluente de frases demonstrariam leitura com compreensão dessas unidades verbais.

Os resultados evidenciam que todos os participantes foram capazes de ordenar as palavras, formando seis novas sentenças, a partir das três sentenças que faziam parte da linha de base, por meio de reforçamento social. Além disso, três participantes apresentaram dificuldades com as sentenças: "UM SAPO COME RÁPIDO" e "O SAPO NADA RÁPIDO". Essa dificuldade poderia ser devida ao fato dessas sentenças apresentarem palavras muito semelhantes, o que reduz a discriminabilidade das duas. Segundo Sidman (1992), “...alguns estímulos podem ser discriminados por causa da sua saliência; ou por que algum controle pelo estímulo seja, talvez, pré-instalado, ou por causa de uma história discriminativa particular do sujeito" (p. 24).

Matos e Hübner (1992) também chamam atenção para essa correspondência entre grafemas e fonemas na língua portuguesa. De acordo com as autoras, "a língua portuguesa tem na maioria das suas palavras, uma correspondência exata entre formas escritas e faladas. .... ou seja, a mesma estrutura fonética e gráfica. .... Com algumas poucas exceções, seus fonemas correspondem aos seus grafemas" (p. 83).

Nos testes de compreensão de leitura com as novas sentenças programadas, os participantes não responderam com compreensão. Na medida em que não houve o ensino das relações condicionais (por exemplo, palavras e figuras)

Tabela 8. Número de respostas corretas pelo número total de respostas requeridas, em cada sentença, para cada participante, nos testes de conectividade I, II e III, do Estudo 2.

\begin{tabular}{lcccc}
\hline \hline Testes de Conectividade & LEO & TER & IVO & MEI \\
\hline Um sapo come rápido (I) & $2 / 2$ & $2 / 2$ & $2 / 2$ & $1 / 1$ \\
UM gato pula muito (I) & $1 / 1$ & $1 / 1$ & $1 / 1$ & $1 / 1$ \\
O sapo nada rápido (II) & $2 / 2$ & $2 / 2$ & $2 / 2$ & $1 / 1$ \\
O urso pula pouco (II) & $1 / 1$ & $1 / 1$ & $1 / 1$ & $1 / 1$ \\
O gato nada muito (III) & $1 / 1$ & $1 / 1$ & $1 / 1$ & $1 / 1$ \\
Um urso come muito (III) & $1 / 1$ & $1 / 1$ & $1 / 1$ & $1 / 1$ \\
\hline
\end{tabular}

Nota - 1/1 participantes responderam na primeira tentativa; $2 / 2$ participantes responderam na segunda tentativa. 
apropriadas e avaliação desse repertório (semântica), os dados evidenciam a ausência desse pré-requisito para essa população, como afirma de Rose (2005): "Para a criança os aspectos semânticos são mais salientes do que os aspectos fonológicos" (p. 37).

\section{Discussão Geral}

O objetivo do presente estudo foi verificar o efeito de dois procedimentos de ensino sobre a composição e compreensão de sentenças em crianças. O ensino de relações condicionais e a formação de classes de estímulos equivalentes (semântica) facilitariam o processo de composição de novas sentenças? Para isso, procurou-se ensinar a formação de três sentenças diferentes com quatro palavras, usando um procedimento de discriminação condicional e, em seguida, por meio de um procedimento de ensino por encadeamento de respostas.

No Estudo 1, os resultados mostraram que todos os participantes submetidos às contingências de ensino de discriminação condicional e por encadeamento, e em seguida a testes comportamentais, responderam consistentemente conforme o ensino na linha de base, formando seis novas sentenças. A posição que cada palavra ocupava na linha de base (artigo, substantivo, verbo e advérbio) parece ter exercido uma função de ordem muito explicitamente na composição das novas sentenças, garantindo uma leitura fluente e com compreensão.

Esses resultados também corroboram a afirmativa de Mackay, Stoddard e Spencer (1989) de que "classes gramaticais que chamamos artigo, nome, verbo e adjetivo podem representar classes funcionais de estímulos que possuem propriedades ordinais" (p. 17). As afirmações desses autores são relevantes porque analisam as relações entre estímulos e entre estímulos e respostas envolvidas nos desempenhos alvo, para ensino e/ou avaliação (Sidman, 1971). O indivíduo precisa ler a palavra seguinte sem deteriorar seu desempenho de leitura da palavra anterior e compreender o significado da frase por inteiro.

O Estudo 2, com quatro crianças, foi planejado para reduzir essa longa exposição aos procedimento de ensino e de testes. Removeu-se o ensino das relações condicionais e testes de equivalência, permanecendo o ensino por encadeamento de respostas para ordenar quatro palavras em três sentenças diferentes. Os resultados mostram que os participantes compuseram seis novas sentenças, a partir da posição de cada palavra, na linha de base, mas não produziram uma leitura fluente com compreensão.

Os dados apresentados no Estudo 1 sugerem que, possivelmente, a formação de classes de equivalência sequencial foi uma condição necessária e suficiente para que tenha ocorrido a construção e leitura de seis novas sentenças, já que os participantes ordenaram as novas sentenças, além de lerem fluentemente e com compreensão. Entretanto, os resultados apontados por Yamamoto (1994) e Yamamoto e Myia (1999), mostram que os participantes ordenaram duas novas palavras na sentença, mas não fizeram uma leitura com compreensão.

No momento, investigações em andamento buscam verificar a expansão de classes sintáticas sob controle condicional.
Por exemplo, dependendo de uma cor presente no ambiente experimental, uma sentença poderia ser construída na voz ativa ou passiva. Testes posteriores avaliarão a emergência de novas sentenças nas vozes ativa e passiva na presença de cores diferentes.

Além do que foi manipulado na presente pesquisa, frisa-se que a compreensão de leitura exigida na escola envolve outras variáveis. Para se avaliar o repertório total de um leitor, em um nível mais elaborado de leitura, seria necessário delinear procedimentos que verificassem níveis mais complexos de leitura, como as habilidades de interpretação, de crítica e de criação de textos.

Pelo exposto, avalia-se que a presente pesquisa aponta indícios da importância teórica e metodológica da investigação da compreensão de leitura na Análise do Comportamento.

\section{Referências}

Assis, G. J. A., Élleres, C. F., \& Sampaio, M. E. C. (2006). Emergência de relações sintáticas em pré-escolares. Interação em Psicologia, 10, 19-29

de Rose, J. C. C. (1993). Classes de estímulos: implicações para uma análise comportamental da cognição. Psicologia: Teoria e Pesquisa, 9, 283-303.

de Rose, J. C. C. (2005). Análise comportamental da aprendizagem de leitura e escrita. Revista Brasileira de Análise do Comportamento, 1, 29- 50.

Green, G., \& Saunders, R. R. (1998). Stimulus equivalence. Em K. Lattal, \& M. Perone, (Orgs.), Handbook of research methods in human operant behavior (pp. 229-262). New York: Plenum Press.

Green, G., Stromer, R., \& Mackay, H. A. (1993). Relational learning in stimulus sequences. The Psychological Record, 43, 599-616.

Lazar, R. M. (1977). Extending sequence-class membership with matching to sample. Journal of the Experimental Analysis of Behavior, 27, 381-392.

Mackay, H. A., Stoddard, L. T., \& Spencer, T. J. (1989). Symbols and meaning classes: Multiple sequence production and the emergence of ordinal stimulus classes. Experimental Analysis of Human Behavior Bulletin, 7, 16-17.

Matos, M. A., \& Hübner, M. M. C. (1992). Equivalence relations and reading. Em S. C Hayes \& L. J. Hayes (Orgs.), Understanding verbal relations (pp. 83-94). Reno: Context Press.

Santos, A. S. L., Silva, A. M. M. V., Baptista, M. Q., \& Assis, G. J. A. (1997). REL 1.0: Sistema computadorizado para o ensino de discriminações simples e condicionais [Resumo]. Em Sociedade Brasileira de Psicologia (Org.), Resumos de comunicações cientificas, XXVII Reunião Anual de Psicologia (p. 192). Ribeirão Preto: SBP

Sidman, M. (1971). Reading and auditory-visual equivalences. Journal of Speech and Hearing Research, 14, 5-13.

Sidman, M. (1992). Equivalence relations: Some basic considerations. Em S. C. Hayes \& L. J. Hayes (Orgs.), Understanding verbal behavior (pp. 15-27). Reno: Context Press.

Sidman. M. (1994). Equivalence relations and behavior: A research story. Boston: Authors Cooperative. 
Sidman, M., \& Tailby, W. (1982). Conditional discrimination vs. matching to sample: An expansion of the testing paradigm. Journal of the Experimental Analysis of Behavior, 37, 5-22.

Stevens, S. S. (1951) Mathematics, measurement and psychophysics. Em S. S. Stevens (Org.), Handbook of experimental psychology (pp. 1-49). New York: John Wiley \& Sons.

Skinner, B. F. (1992). Verbal behavior. Acton: Copley. (Trabalho original publicado em 1957)

Yamamoto, J. (1994). Functional analysis of verbal behavior in handicapped children. Em S. C. Hayes, L. J. Hayes \& K. O. Sato (Orgs.), Behavior analysis of language and cognition (pp. 107-122). Reno: Context Press.
Yamamoto, J., \& Miya, T. (1999). Acquisition and transfer of sentence construction in autistic students: Analysis by computerbased teaching. Research in Developmental Retardation, 20, 355-377.

Recebido em 19.06.08 Primeira decisão editorial em 20.01.09 Versão final em 28.01.09 Aceito em 10.03.09 